\title{
Heartbeat: time to address sexism and sexual harassment
} in cardiology

The proportion of cardiologists who are women remains low despite many decades of equal numbers of men and women entering medical school and continues to lag behind other medical specialties with respect to workforce representation. To further define the barriers and challenges facing women who choose to specialise in cardiology, Jaijee and colleagues ${ }^{1}$ used a validated questionnaire sent to 890 UK consultant cardiologists to measure experiences of sexism and sexual harassment. In contrast to sexual harassment, sexism is defined as acts, words or behaviours that imply a person is inferior because of their sex. Of the 174 respondents, 24\% were female. Overall, 62\% of female cardiologists experienced some type of discrimination, most often related to gender and parenting, compared to $20 \%$ of male cardiologists. Sexual harassment affected professional confidence in $43 \%$ of women compared to $3 \%$ of men. In addition, sexism limited opportunities for professional advancement in $33 \%$ of female cardiologists compared to $2 \%$ of male cardiologists.

In the accompanying editorial, BabuNarayan and Ray $^{2}$ discuss the perceived and actual barriers to improved representation of women in cardiology. 'There is no doubt that cardiology requires drive, dedication and commitment, but these should not be conflated with a requirement for excessively long working hours, 'presenteeism' and the exclusion of outside interests and family life either for men or for women.' Underrepresentation of women does matter. 'Lack of diversity of the leadership stifles creativity and innovation and gender inequality may help sexism or sexual harassment go unchallenged. Missing out on talent could cost lives.' As they conclude 'Effective strategies proven to mitigate the unwanted effects of gender or other stereotypes on women or men in cardiology are needed. These must address structural barriers to entry, to pay and to career progression in cardiology including

Division of Cardiology, University of Washington, Seattle, Washington, USA

Correspondence to Professor Catherine M Otto, Division of Cardiology, University of Washington, Seattle, WA 98195, USA; cmotto@uw.edu
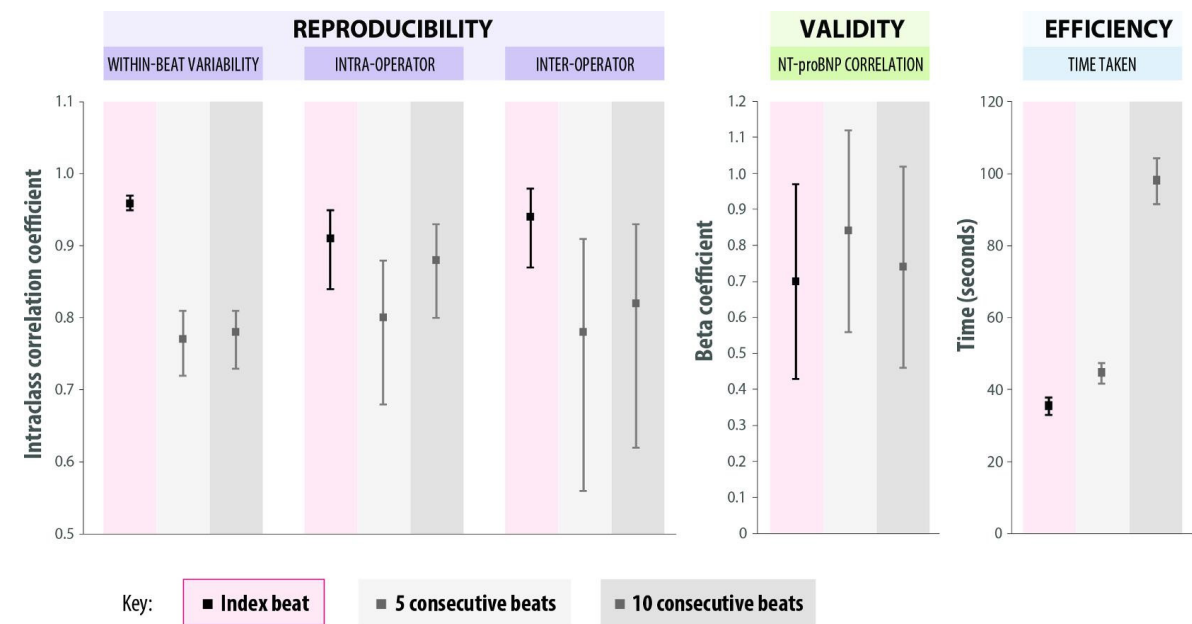

Figure 1 Reproducibility, validity and time efficiency of the index-beat approach for E/e'. Comparison of the index-beat method verses averaging of 5 and 10 consecutive beats for: (1) reproducibility (ICC and 95\% CI for within-beat, intraoperator and interoperator variability); (2) validity (beta coefficient for NT-proBNP with $95 \% \mathrm{Cl}$ ); and (3) time taken to measure E/e' (mean seconds, with $95 \% \mathrm{CI}$ ). E/e', mitral E wave max/average diastolic tissue Doppler velocity from the septal and lateral annulus; ICC, intraclass correlation coefficient; NT-proBNP, N-terminal pro-B-type natriuretic peptide.

in academic cardiology, and may include continued and robust analysis of genderrelated and intersectional pay disparity, transparency of metrics for and access to promotion, fair performance evaluation

for assessment for additional renumeration, investment in childcare, centralised budgets for parental leave and incentives to existing leaders to address the imbalance. Sexism and sexual harassment by

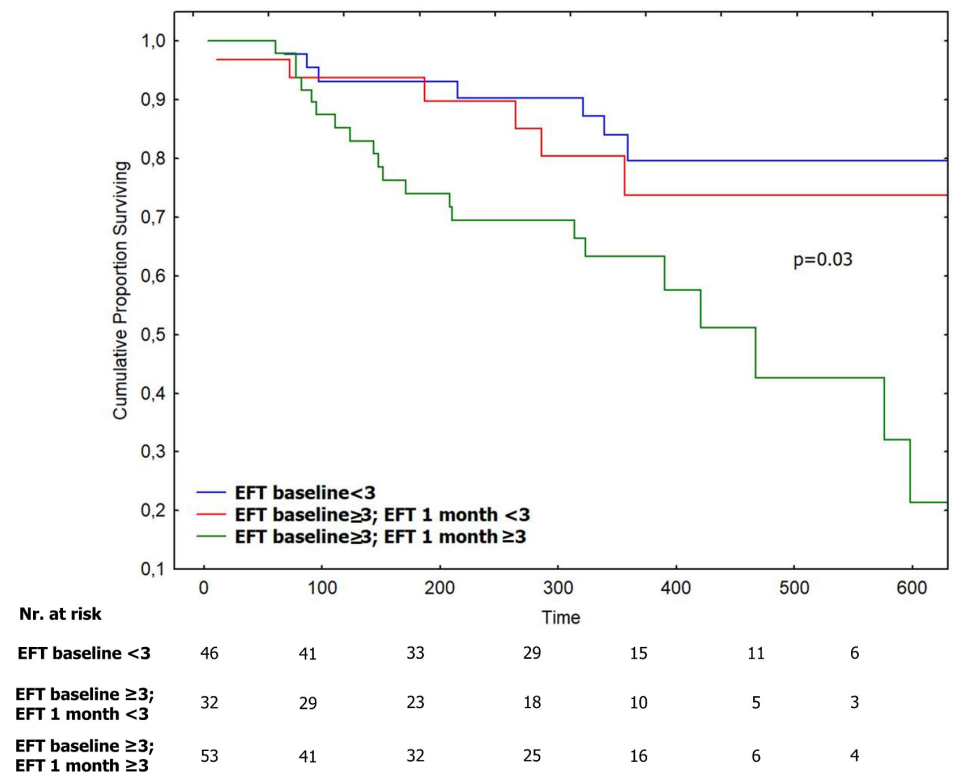

Figure 2 Cumulative survival of patients bridged to TAVI stratified according to EFT baseline and 1-month values. EFT, essential frailty toolset; TAVI, transcatheter aortic valve replacement. 
SUMMARY OF ESC 2019 RECOMMENDATIONS: LONG-TERM ANTITHROMBOTIC THERAPY IN PATIENTS WITH CCS

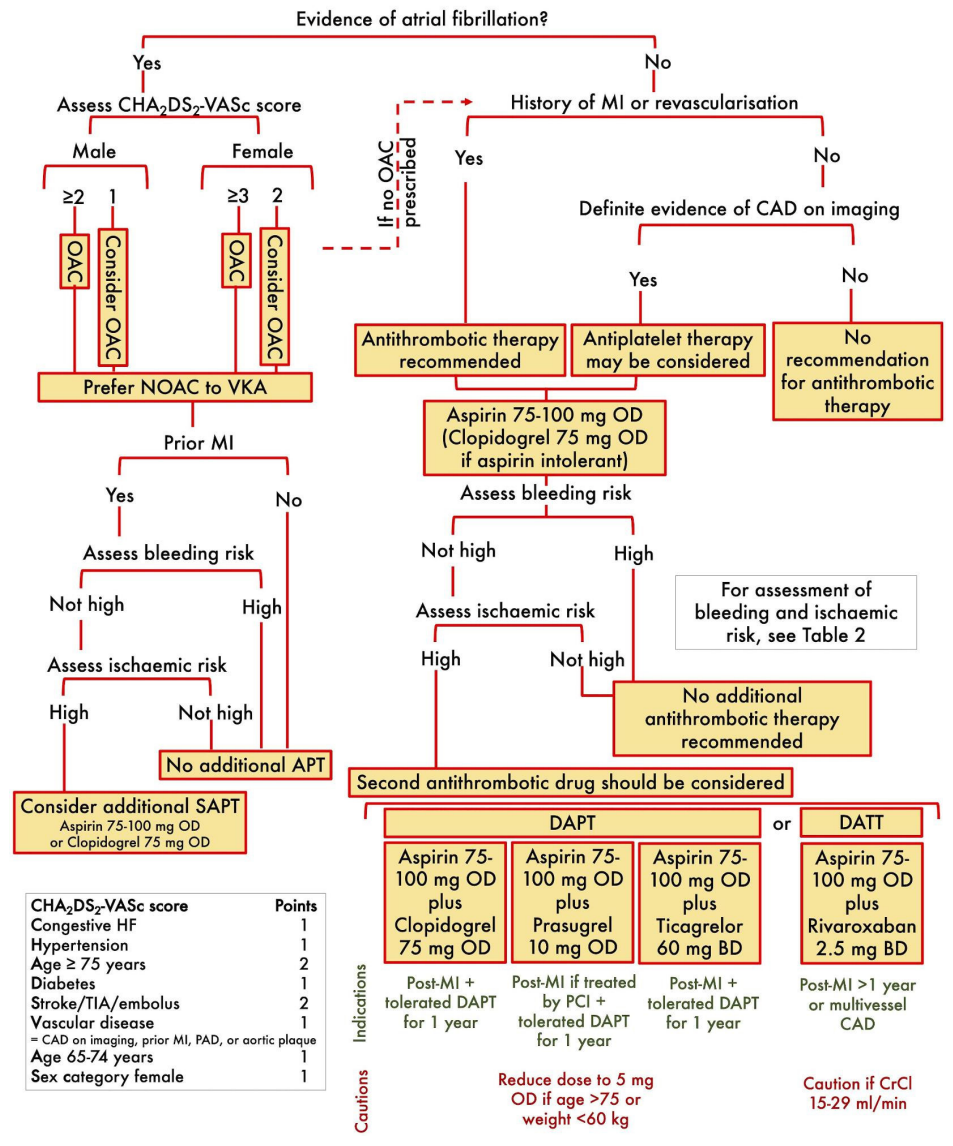

Figure 3 Decision algorithm summarising the approach to determining an optimum regimen of antithrombotic regimen suggested in the ESC 2019 CCS guidelines. APT, antiplatelet therapy; $B D$, twice daily; $C A D$, coronary artery disease; $C C S$, chronic coronary syndrome; $\mathrm{CrCl}$, creatinine clearance; DAPT, dual antiplatelet therapy; DATT low-dose dual antithrombotic therapy; ESC, European Society of Cardiology; HF, heart failure; Ml, myocardial infarction; NOAC, non-vitamin $\mathrm{K}$ antagonist oral anticoagulant; $\mathrm{OAC}$, oral anticoagulant; $\mathrm{OD}$, once daily; $\mathrm{PAD}$, peripheral artery disease; $\mathrm{PCl}$, percutaneous coronary intervention; SAPT, single antiplatelet therapy; TIA, transient ischaemic attack; VKA, vitamin $\mathrm{K}$ antagonist.

women or men are no more acceptable in cardiology than anywhere else and must no longer be tolerated.'

Heart failure (HF) is present or will develop in up to $50 \%$ of patients with atrial fibrillation $(\mathrm{AF})$. However, the

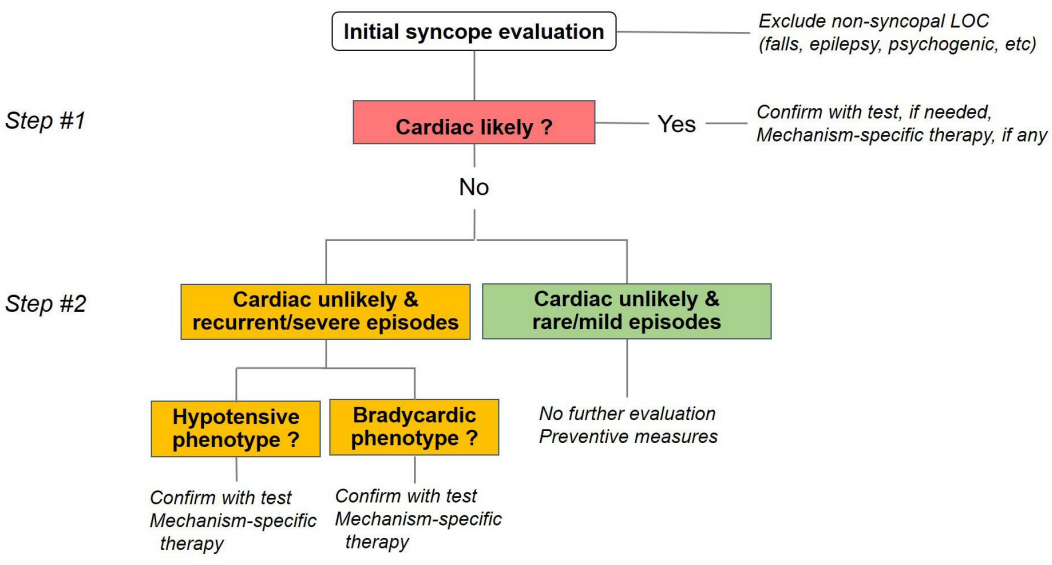

Figure 4 The management of a patient with syncope based on risk stratification. LOC, loss of consciousness. echocardiographic diagnosis of $\mathrm{HF}$ in patients with AF is complicated by the beat-to-beat variability in measures of ventricular function with an irregular heart rhythm. In a series of 160 patients with AF, Bunting and colleagues ${ }^{3}$ found that measurements of LV function based on a single index beat improved reproducibility and saved time compared to averaging 5-10 consecutive beats, with no effect on validity compared to natriuretic peptide levels (figure 1). The index beat approach is simply to measure a single cardiac cycle that follows two preceding $\mathrm{R}-\mathrm{R}$ intervals of similar duration.

Minners and Jander ${ }^{4}$ comment that this data convincingly shows that the index-beat approach is more reproducible and quicker than averaging several consecutive beats. However, they caution that ventricular function may be underestimated if the index beat is not representative of overall heart rate. On the other hand, 'In clinical practice, the vast majority of echocardiography departments (including our own) assesses a 'typical' or representative beat whereby the echocardiographer chooses a single beat considered characteristic of the patient's haemodynamic situation.' 'Further work, such as the one presented by Bunting et $a l^{3}$ is clearly required to improve parameters of reproducibility, validity, as well as clinical applicability and relevance in our commitment to optimise care in patients with $\mathrm{AF}$ and heart failure.'

Balloon aortic valvuloplasty (BAV) continues to be performed in a small subset of patients, particularly those who require stabilisation prior to transcatheter aortic valve implantation (TAVI). Tumscitz and colleagues ${ }^{5}$ report the safety, efficacy and impact of frailty on outcomes after BAV using a minimally invasive radial artery approach (figure 2). The essential frailty toolset (EFT) provides a composite score from 0 to 5 based a chair test, cognition, haemoglobin and albumin. An EFT score of three or higher is associated with increased mortality.

Commenting on this study, Bongiovanni and Presbitero ${ }^{6}$ raise the question of whether BAV still has a place in the TAVI era. Their answer is: 'Certainly, it will be an important procedure in different settings: first, to evaluate the clinical impact of transvalvular gradient reduction in patients with reduced ejection fraction and unclear functional reserve before definitive TAVI therapy; second, to allow urgent major surgery in severely ill patients with unclear prognosis; third, as a bridge to decision or to definitive 
surgical or percutaneous treatment in countries with limited technologies and budget.'

The Education in Heart article in this issue summarises the approach to antithrombotic therapy in patients with chronic coronary syndromes. ${ }^{7}$ Key steps in the rather complex decision-making process are the presence of atrial fibrillation; prior myocardial infarction, revascularisation or definite coronary artery disease on imaging; bleeding risk; and ischaemic risk (figure 3).

A comprehensive review article in this issue of Heart provides a detailed approach to diagnosis and therapy of syncope (figure 4). Several algorithms provide a roadmap for patient management that will be of great value to clinicians. ${ }^{8}$
Funding The authors have not declared a specific grant for this research from any funding agency in the public, commercial or not-for-profit sectors.

Competing interests None declared.

Patient and public involvement Patients and/or the public were not involved in the design, or conduct, or reporting, or dissemination plans of this research.

Patient consent for publication Not required.

Provenance and peer review Commissioned; internally peer reviewed.

(C) Author(s) (or their employer(s)) 2021. No commercial re-use. See rights and permissions. Published by BMJ.

\section{(D) Check for updates}

To cite Otto CM. Heart 2021;107:855-857.

Heart 2021;107:855-857.

doi:10.1136/heartjnl-2021-319556

\section{ORCID ID}

Catherine M Otto http://orcid.org/0000-0002-05279392

\section{REFERENCES}

1 Jaijee SK, Kamau-Mitchell C, Mikhail GW, et al. Sexism experienced by consultant cardiologists in the United Kingdom. Heart 2021;107:895-901.

2 Babu-Narayan SV, Ray S. Women in cardiology: no progress in the pace of change. Heart 2021;107:860-1.

3 Bunting KV, Gill SK, Sitch A. Improving the diagnosis of heart failure in patients with atrial fibrillation. Heart 2021;107:902-8.

4 Minners J, Jander N. Consecutive, index and representative beats: obtaining reliable information despite an irregular heart rhythm. Heart 2021;107:862-3.

5 Tumscitz C, Di Cesare A, Balducelli M, et al. Safety, efficacy and impact on frailty of mini-invasive radial balloon aortic valvuloplasty. Heart 2021;107:874-80.

6 Bongiovanni D, Presbitero P. Does radial balloon aortic valvuloplasty have a place in the TAVI era? Heart 2021;107:858-9.

7 Parker WAE, Storey RF. Antithrombotic therapy for patients with chronic coronary syndromes. Heart 2021;107:925-33.

8 Brignole M, Rivasi G. New insights in diagnostics and therapies in syncope: a novel approach to non-cardiac syncope. Heart 2021;107:864-73. 